\title{
A TRAVÉS DEL RÍO DEL CAMBIO
}

\author{
Ronald L. Bishop, Erin L. Sears y M. James Blackman \\ Smithsonian Institution*
}

\section{Introducción}

Las elevaciones y caídas del río Usumacinta, junto con sus principales afluentes, como el río Pasión y el San Pedro Mártir, ofrecían un medio de comunicación accidentado entre los mayas que habitaban en esta cuenca hidrológica (figura 1). Estas vías fluviales fueron un factor relevante en el desarrollo de acontecimientos históricos entre las poblaciones de estas zonas, $\mathbf{y}$ han sido relacionadas con el colapso social y el abandono de amplias áreas de la región maya central a finales del siglo octavo de nuestra era. Los hechos ocurridos pueden ser monitoreados en parte a través del estudio del desarrollo y el patrón de aparición de materiales cerámicos. No obstante, los métodos convencionales de clasificación cerámica con frecuencia son inadecuados para brindar información lo suficientemente precisa respecto a la distribución, en particular acerca de importantes matices arqueológicos del desarrollo, elaboración y cambio de materiales cerámicos. Con la finalidad de aportar información complementaria a la derivada de enfoques más tradicionales, nos basamos en datos que son resultado de la aplicación extensiva de la activación neutrónica en el análisis de las cerámicas mayas negro fino, gris fino y anaranjado fino, en especial según su asociación con asentamientos localizados en la cuenca del Usumacinta y la región de Palenque, en el occidente de las Tierras Bajas Mayas. ${ }^{1}$

\section{Antecedentes analíticos}

La aparición de la cerámica de pasta fina, especialmente la loza anaranjado fino (figura 2) en la época de la caída de las grandes capitales mayas de Piedras Negras, Altar de Sacrificios y Ceibal, entre otros, da lugar a especulaciones acerca de los orígenes de esta clase de cerámica y del papel que tuvo el río. De acuerdo

\footnotetext{
- Programa de Arqueometría, Departamento de Antropología, Smithsonian Institution y National Museum of Natural History, MRC 112.

${ }^{1}$ Quisiéramos expresar nuestro profundo agradecimiento a los oficiales del Instituto Nacional de Antropología e Historia de México y del Museo Nacional de Antropología y Etnología de Guatemala, ya que ellos nos dieron acceso a la información y a la colección en ésta y otras ocasiones anteriores. Esta información nos permitió desarrollar e integrar este trabajo multidisciplinario. Sin la facilidad de acceder a las colecciones de los museos, los centros regionales y los proyectos arqueológicos en la zona maya, este programa de investigación no habría sido posible. Gracias a todos.
} 


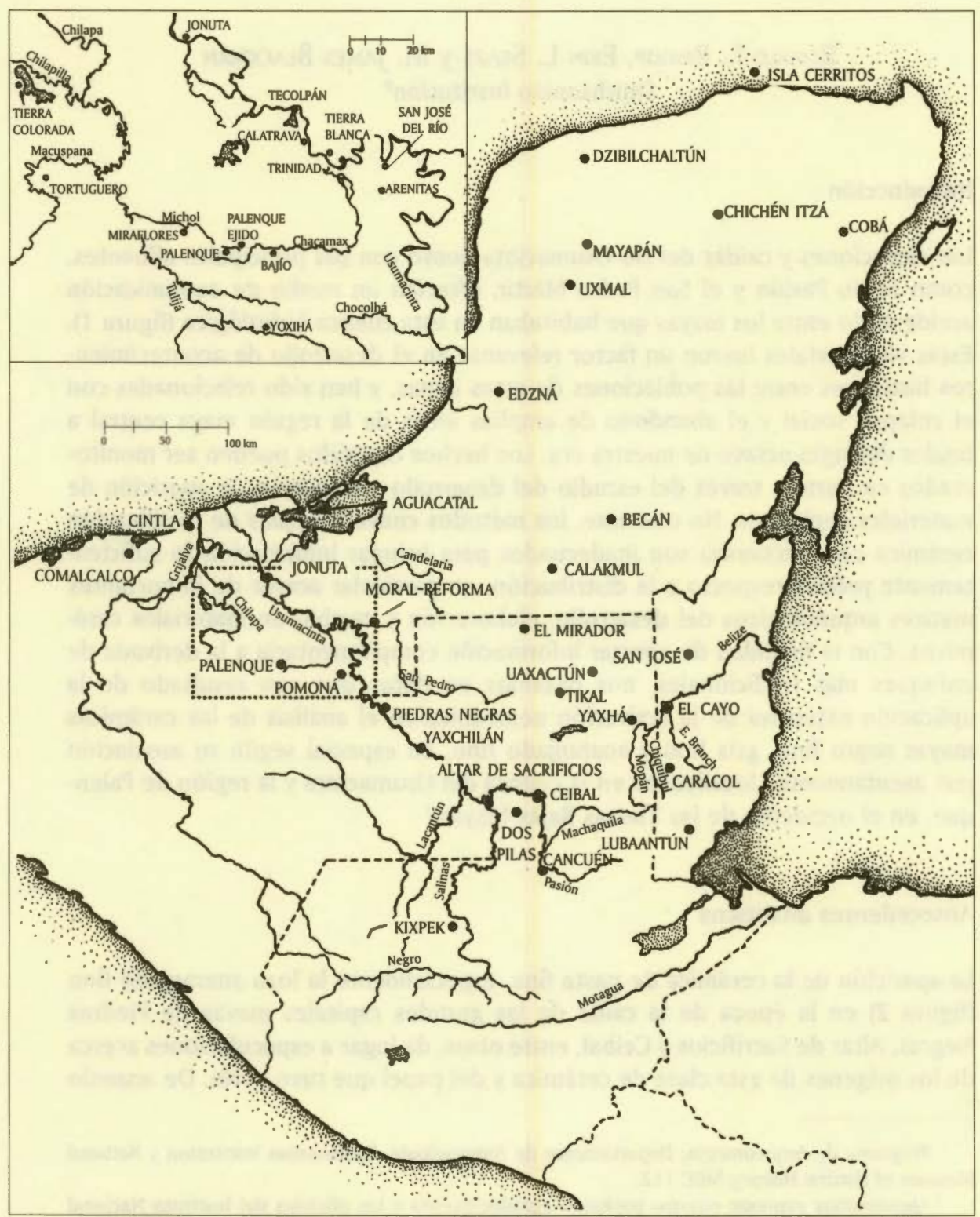

Figura 1. MAPA DEL ÁreA mostrando los sitios de donde provienen las muestras sometidas a análisis químicos 


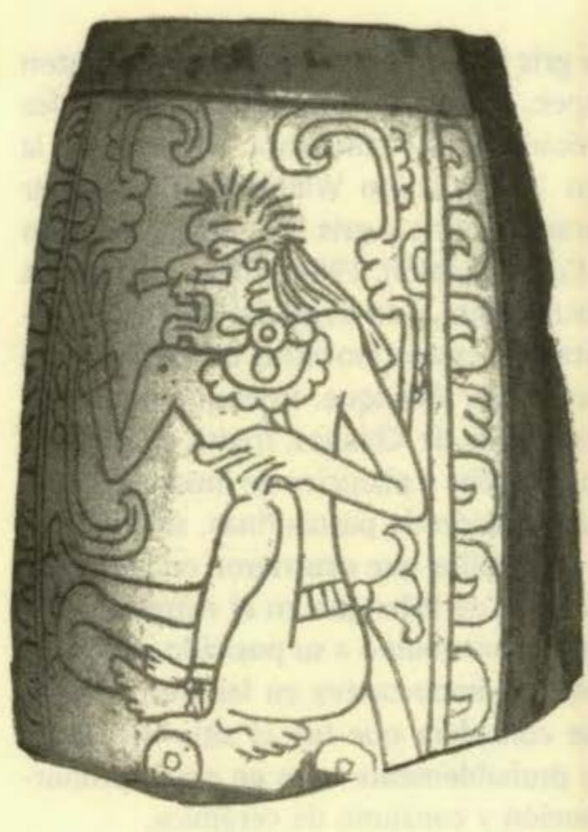

a

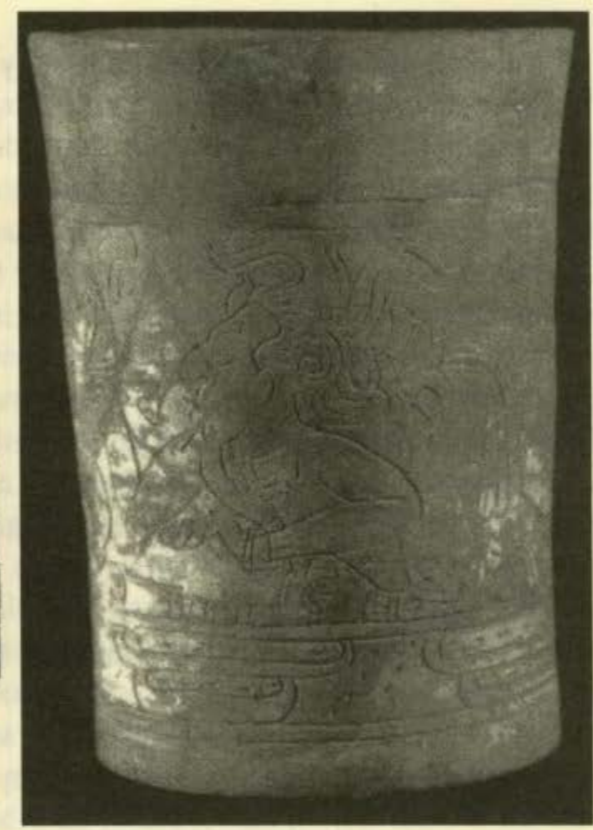

b

Figura 2. Loza anaranjado fino. a. "Putún de cabellera larga" en el tipo Provincia Plano Relieve (Museo de Jonuta); b. cerámica fina café-anaranjado (Proyecto Palenque/Centro INAH Chiapas)

con las investigaciones previas de Robert E. Smith (1958) y Heinrich Berlin (1956), se consideró que Tabasco y Campeche, en la zona del Golfo de México, probablemente fueron las fuentes de esta loza tardía. La presencia de este tipo de cerámica, asociada con otras evidencias materiales (i. e. características estilísticas "foráneas"), sirvió de base para sustentar hipótesis acerca de incursiones de grupos no mayas del Clásico, por ejemplo el desplazamiento de los "putunes de cabellera larga" (figura 2a) en la vertiente del Pasión-Usumacinta, como posibles factores del colapso de las unidades sociopolíticas del alto Usumacinta (cfr. Adams, 1971, 1973a; Sabloff, 1973, 1975; Rands, Bishop y Sabloff, 1982). Las interrogantes relativas al número y localización de los centros productores y la necesidad de fundamentar el movimiento de cerámica de pasta fina, desde las fuentes hasta los sitios donde se piensa que fue intrusiva, se convirtieron en la base para uno de los programas analíticos de mayor duración llevados a cabo, que usa la INAA como método para la caracterización de pastas. ${ }^{2}$

${ }^{2}$ De manera rutinaria, en las instalaciones que el Smithsonian tiene en el National Institute of Standards and Technology, las concentraciones elementales de las pastas cerámicas se producen con una precisión analítica alta y gran sensibilidad, determinándose varias concentraciones elementales 
Las cerámicas mayas anaranjado fino y gris fino de las excavaciones de Linton Satherwaithe en Piedras Negras y de Kixpec, fueron de los primeros materiales analizados por INAA a principio de la década de los cincuenta. Después de la publicación de estos análisis iniciales, en 1966 Gordon Willey sugirió ampliar la investigación para incluir las lozas anaranjado fino y gris fino recuperadas en las excavaciones de Altar de Sacrificios y Ceibal (Sabloff, 1982), sitios localizados en las cuencas altas de la vertiente del Usumacinta, a lo largo del río Pasión.

Posteriormente, Robert Rands fue invitado a enviar muestras de cerámica de pasta fina de sus investigaciones en la región de Palenque. Palenque está localizado en la primera elevación de las tierras altas de Chiapas, frente a las planicies bajas al norte, que son la transición a los sitios y planicies de inundación del bajo Usumacinta. Palenque tuvo una larga tradición de pastas finas, siendo esto uno de los aspectos relacionados con los desarrollos que ocurrieron en las regiones del bajo y medio Usumacinta. La ubicación de Palenque en el extremo occidental de la vertiente hidrológica pudo haber contribuido a su posición periférica en relación con los desarrollos cerámicos más importantes en las tierras bajas centrales del área maya, sobre todo si se considera que fue el sitio de mayor importancia de la región, por lo que muy probablemente tuvo un papel primordial en la innovación, elaboración, distribución y consumo de cerámica.

En el período Murciélagos de Palenque, el cual siguió a la muerte de K'inich Janaab'Pakal I, circa 683 d.C., la cerámica de pasta fina con paredes delgadas, con engobe y pintada, fue importada en grandes cantidades y también se manufacturó localmente. La cerámica con pasta bayo-crema quizá fue importada desde sitios localizados a lo largo de la parte baja del Usumacinta. Para otras clases de cerámica, que muestran un buen control en la técnica de formado de las vasijas, el resultado son piezas de paredes muy delgadas con pasta fina de color caféanaranjado (figura $2 \mathrm{~b}$ ), incluyendo vasijas de silueta cilíndrica finamente incisas. Las cerámicas finas café-anaranjado a menudo contienen fitolitos opalinos, formados en plantas que acumulan silicatos y que crecen en áreas de drenaje pobre. La cerámica café-rojiza, que cronológicamente abarca buena parte de la secuencia de Palenque, no tiene inclusiones fitolíticas, lo cual indica que las cerámicas que comúnmente contienen abundantes fitolitos, en consecuencia, tal vez no fueron hechas en el mismo Palenque. Lo más probable es que para su producción se emplearan materias primas que se encuentran en la base de las elevaciones, en donde eran favorables las condiciones para la acumulación de fitolitos.

en el nivel de partes por millón o por debajo de éste. Sin embargo, independientemente del cuidado con que se colectan estos datos, lo poco adecuado del muestreo puede limitar hasta qué punto los datos son susceptibles de una evaluación e interpretación estadística rigurosa. Si es de interés aproximarnos a una interpretación precisa de la historia maya en la región, a menudo debemos entretejer las evidencias que se presentan como hilos aislados, hasta obtener redes de significados que se fundamenten al hacer uso del mayor número posible de conjuntos de datos complementarios. 
En los inicios del siguiente período de Palenque, el Balunté (circa 750-810 d. C.), abundan nuevas formas de piezas de pasta fina, como los cajetes curvo divergentes (copas) y piezas negras manchadas, lustrosas, de cocción uniforme (loza negro fino, figura 3a). Parte de estos materiales cerámicos, además de que contiene fitolitos, también presenta partículas finas de vidrio volcánico, inclusiones que sugieren un área de procedencia algo más alejada hacia el norte de Palenque. También es abundante la loza gris fino, representada por miembros del grupo cerámico Chablekal (figura 3 b, c, d). La cerámica gris fino está representada por vasijas sin decoración, mientras que otras muestran ornamentación similar a la del negro fino. Hay múltiples atributos de la decoración zonal negra, el acanalado bajo el borde y el estampado dentado, que son propios de los tipos más elaborados (por ejemplo, Chicxulub Inciso [figura 3 b, c] y Teichac Compuesto [figura 3d]).

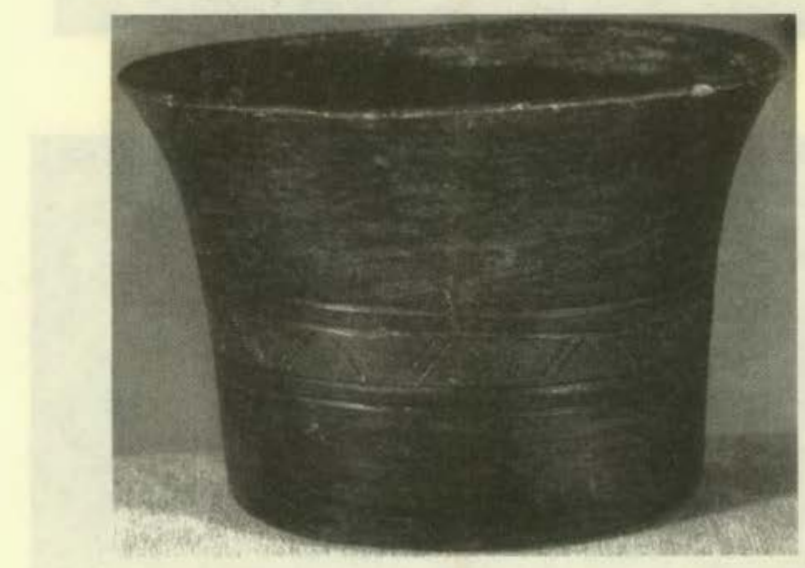

a

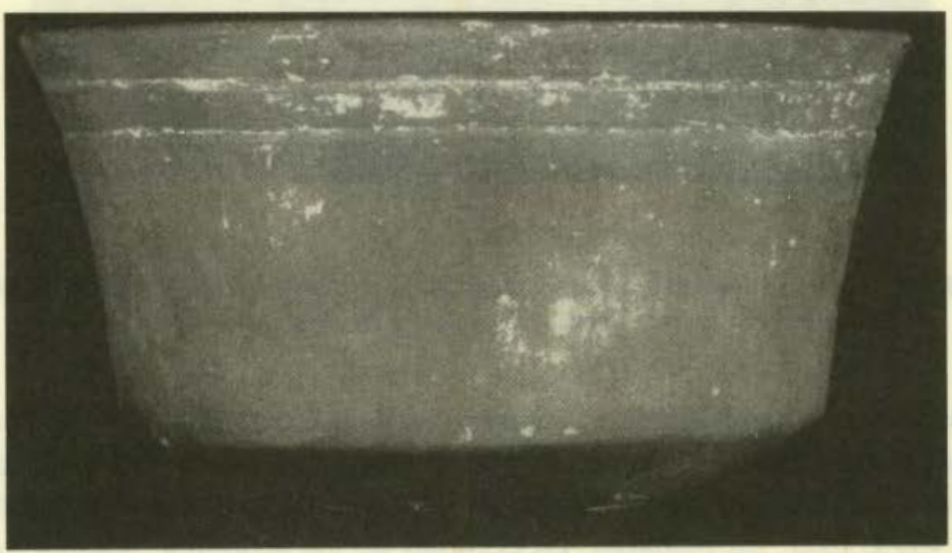

b 


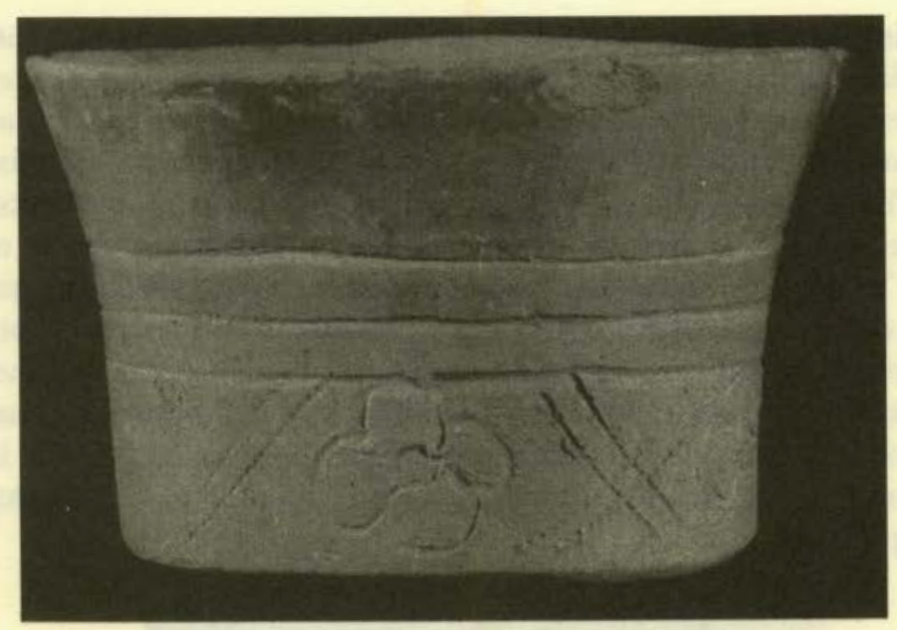

c

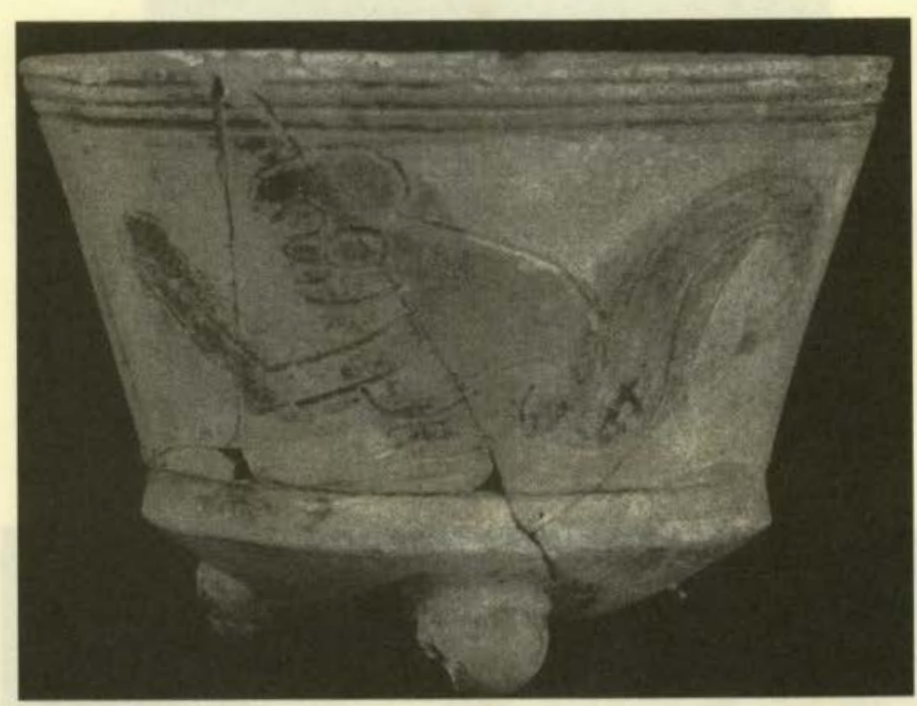

d

Figura 3. LozA negro fino y gris fino. a. negro fino, Grupo Cerámico Yalcox; b y c. Tipo Chicxulub Inciso; d. Tipo Telchac Compuesto (Proyecto Palenque/Centro INAH Chiapas)

En Palenque se han identificado materiales de la loza anaranjado fino, aunque en menores cantidades que la cerámica gris fino, ubicados cronológicamente en un período posterior a aquel cuando se inició el abandono del asentamiento (Rands, 1973: 192). Sin embargo, en el corpus de los atributos decorativos de la loza anaranjado fino, especialmente en lo que respecta al grupo cerámico Balan- 
cán, observamos elementos reminiscentes de la cerámica fina café-anaranjado del período Murciélagos. De esta manera, de entre la cerámica recuperada en el área de Palenque se encuentra aquella que, en términos decorativos, formales y características de las pastas, permite relacionar este centro maya occidental con una región más amplia, que incluye la del Usumacinta.

En 1973, Bishop empezó a realizar análisis de cerámica de pasta fina que incluía anaranjado fino (cerámica Balancán, Altar y Silhó), gris fino (Tres Naciones y el grupo Chablekal) y negro fino (grupo Yalcox). En el curso de los años, el proyecto se ha ampliado geográficamente mediante un muestreo extensivo de los sitios de las tierras bajas del noroeste que recorrió Lorenzo Ochoa (1976), las tierras bajas del norte y de sitios que se localizan en toda la región nuclear maya.

Palenque y la región de la vertiente del Usumacinta resultaron de mayor interés para estudiar el desarrollo y el movimiento interregional de cerámica, como consecuencia de los programas de excavación llevados a cabo en el área guatemalteca del Lago Petexbatún y en Cancuén, río arriba del Pasión, desde Ceibal (figura 1). Las excavaciones de Arroyo de Piedra, Aguateca y otros sitios en el Petexbatún revelaron la presencia de cerámica gris fina Chablekal (figura 4). Cuando se realizaron análisis de INAA de la cerámica gris fina del Petexbatún, se descubrió una fuerte semejanza química con materiales de la loza gris fino Chablekal recuperados en la región de Palenque.

La aparente relación entre el Petexbatún y la región de Palenque resultó intrigante. Además, este misterio se agudizó a raíz de que se encontraron fragmentos de cientos de vasijas de gris fino Chablekal en Cancuén. Los análisis químicos de la cerámica gris fino de Cancuén permitieron establecer que es similar en composición a la gris fino del Petexbatún, al igual que a parte de la cerámica gris fino de Palenque. Curiosamente, aunque se ha encontrado cerámica gris fino en Altar de Sacrificios y Ceibal, está compuesta predominantemente de gris fino Tres Naciones, una variante tardía sin oxidación de la pasta del anaranjado fino. La cerámica Chablekal está representada en Altar solamente por seis tiestos no identificados (Adams, 1971: figura 72b) y no ha sido reportada para el caso de Ceibal (Sabloff, 1975). El posible movimiento de esta cerámica distintiva río arriba por la cuenca del Usumacinta y hacia el río Pasión, y el hecho de que se encontrara en algunos sitios en cantidades más significativas que otros materiales, justo antes de finales del siglo octavo, nos llevó a plantear que se requerían más investigaciones para determinar cuáles fueron los lugares donde se produjo.

\section{Análisis de datos composicionales}

Antes de la discusión de los patrones composicionales de la cerámica gris fino o negro fino, presentamos un breve resumen de los hallazgos analíticos para la 


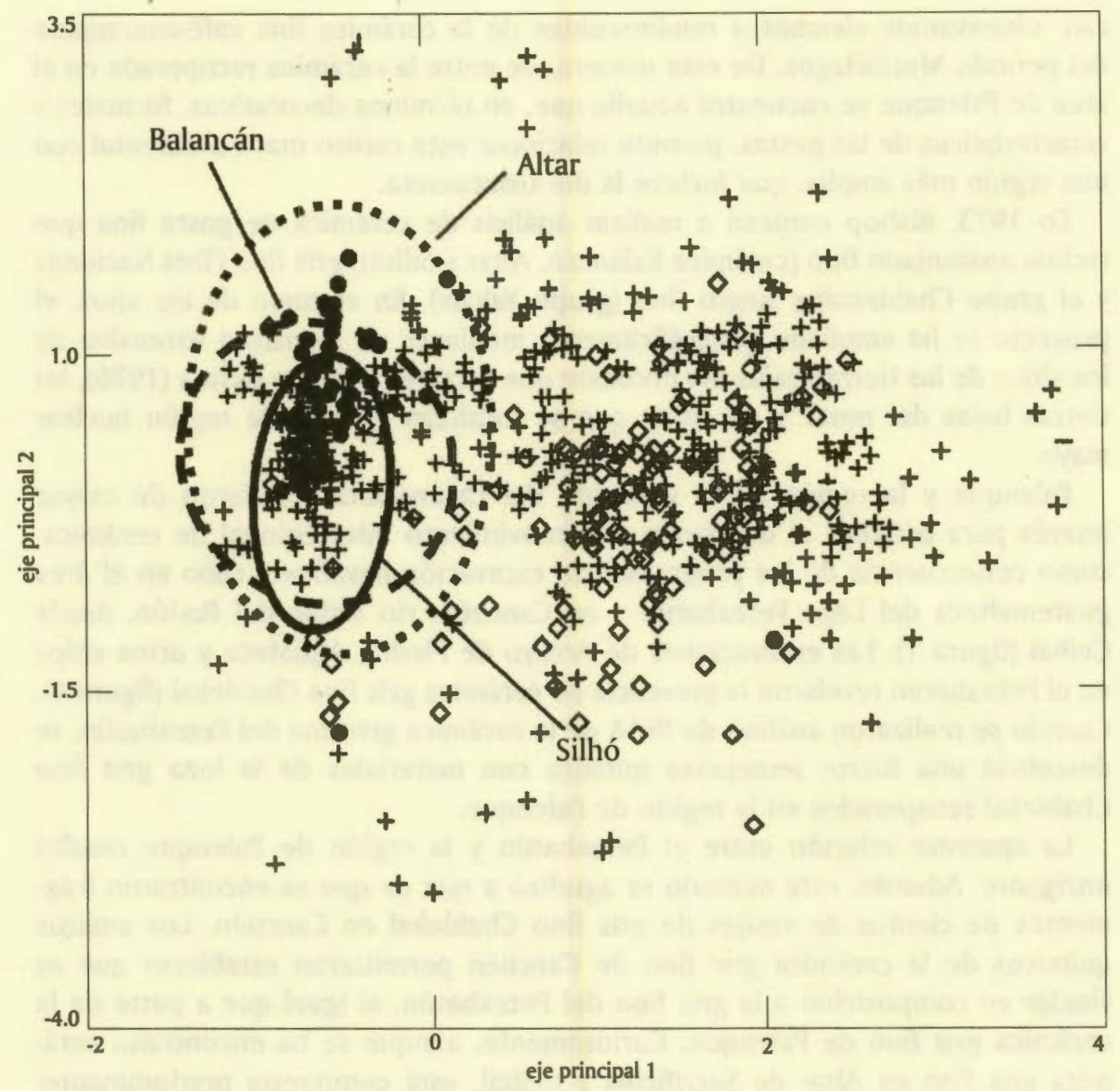

Figura 4. Gráfica de los componentes principales para el total del conjunto de datos dE la Cerámica de PASTa Fina. Los valores de los componentes se enlistan en la tabla 2

loza anaranjado fino y su contraparte, gris fino Tres Naciones. Hacemos uso de este "orden invertido", lógicamente para el análisis, debido a la relativa claridad de los datos para la loza anaranjado fino, pues así se cuenta con un patrón de referencia para realizar la discusión acerca de las composiciones de la cerámica negro fino y gris fino Chablekal.

\section{Loza anaranjado fino}

Desde principio de la década de los noventa, la cerámica anaranjado fino (FO) de los grupos cerámicos Altar, Balancán y Silhó se ha asociado con certeza a fuentes de producción ubicadas a lo largo de afluentes del bajo Usumacinta (Bishop, 
1994). Los datos derivados de los análisis de arcillas del Usumacinta, con muestras recolectadas en distintos lugares, son afines química y mineralógicamente (con matriz micácea y frecuentes partículas finas de ceniza volcánica) a la cerámica anaranjado fino, lo cual fundamenta relaciones que, de otra manera, se habrían sustentado con el criterio de abundancia. Se han definido dos grupos composicionales principales con lugares de producción en el bajo Usumacinta. En este estudio los resultados se presentan en gráficas que ilustran análisis discri-. minantes de los datos químicos (figura 5 ; tabla 1 ).

La cerámica del grupo anaranjado fino-sur (FO-sur) al parecer se manufacturó en una zona relativamente restringida, que incluye los sitios de Jonuta, Tecolpán y Calatrava (figura 1). La pertenencia tipológica en este grupo composicional presenta un sesgo en el caso del grupo cerámico Balancán, en especial el tipo Provincia Plano Relieve, una cerámica que floreció casi a finales del período

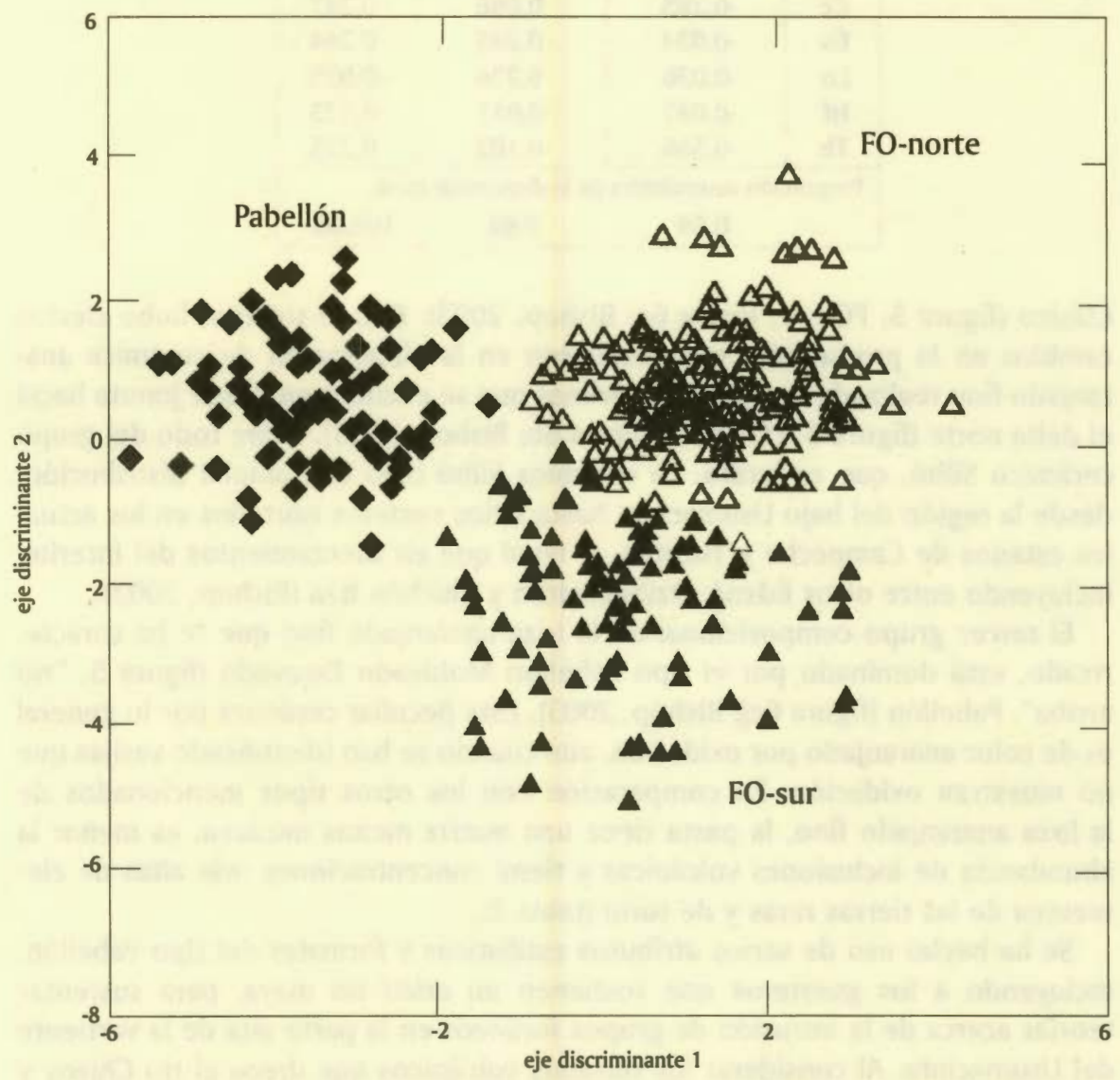

Figura 5. Grupos de anaranjado fino. Gráfica del análisis discriminante de los ejes 1 y 2 
TABLA 1

FUNCIONES DISCRIMINANTES CANÓNICAS

ESTANDARIZADAS POR LA VARIANZA

\begin{tabular}{|c|c|c|c|}
\hline & Df. 1 & Df. 2 & Df. 3 \\
\hline $\mathrm{Na}$ & 0.264 & 0.138 & 0.431 \\
\hline K & -0.358 & 0.180 & -0.361 \\
\hline Sc & 0.038 & -0.056 & 0.775 \\
\hline $\mathrm{Cr}$ & -0.275 & 0.153 & 0.392 \\
\hline $\mathrm{Fe}$ & 0.304 & -0.401 & -0.295 \\
\hline Co & -0.159 & 0.134 & 0.110 \\
\hline $\mathrm{Rb}$ & -0.285 & 0.037 & -0.404 \\
\hline Cs & 0.069 & 0.245 & -0.216 \\
\hline $\mathrm{Ba}$ & -0.139 & -0.960 & 0.221 \\
\hline La & 0.135 & -0.255 & -0.016 \\
\hline $\mathrm{Ce}$ & -0.285 & 0.086 & -0.247 \\
\hline Eu & -0.034 & 0.245 & 0.244 \\
\hline Lu & -0.036 & 0.226 & -0.025 \\
\hline $\mathrm{Hf}$ & -0.087 & -0.011 & 0.175 \\
\hline Th & -0.586 & 0.102 & 0.225 \\
\hline \multicolumn{4}{|c|}{ Proporción acumulativa de la dispersión total: } \\
\hline & 0.54 & 0.88 & 100.00 \\
\hline
\end{tabular}

Clásico (figura 5, FO-sur; figura 6a; Bishop, 2003). Con el tiempo, hubo ciertos cambios en la producción, que resultaron en la elaboración de cerámica anaranjado fino realizada con materias primas que se encuentran desde Jonuta hacia el delta norte (figura 5, FO-norte; figura 6b; Bishop, 2003), sobre todo del grupo cerámico Silhó, que es tardío. La cerámica Silhó tuvo una amplia distribución, desde la región del bajo Usumacinta hasta sitios costeros norteños en los actuales estados de Campeche y Yucatán, al igual que en asentamientos del interior, incluyendo entre otros Edzná, Dzibilchaltún y Chichén Itzá (Bishop, 2003).

El tercer grupo composicional de la loza anaranjado fino que se ha caracterizado, está dominado por el tipo Pabellón Moldeado Excavado (figura 5, "río arriba", Pabellón [figura 6c]; Bishop, 2003). Ésta peculiar cerámica por lo general es de color anaranjado por oxidación, aun cuando se han identificado vasijas que no muestran oxidación. En comparación con los otros tipos mencionados de la loza anaranjado fino, la pasta tiene una matriz menos micácea, es menor la abundancia de inclusiones volcánicas y tiene concentraciones más altas de elementos de las tierras raras y de torio (tabla 2).

Se ha hecho uso de varios atributos estilísticos y formales del tipo Pabellón, incluyendo a los guerreros que sostienen un atlatl no maya, para sustentar teorías acerca de la intrusión de grupos foráneos en la parte alta de la vertiente del Usumacinta. Al considerar los terrenos volcánicos que drena el río Chixoy y la descarga de sedimentos en el Usumacinta, Bishop y Rands propusieron que la 


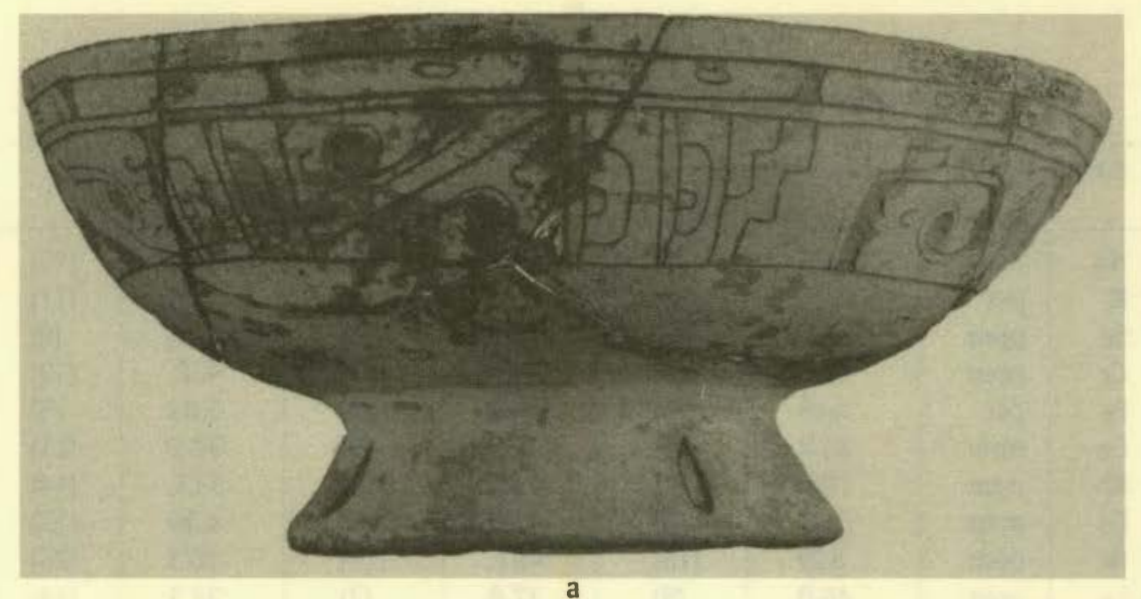

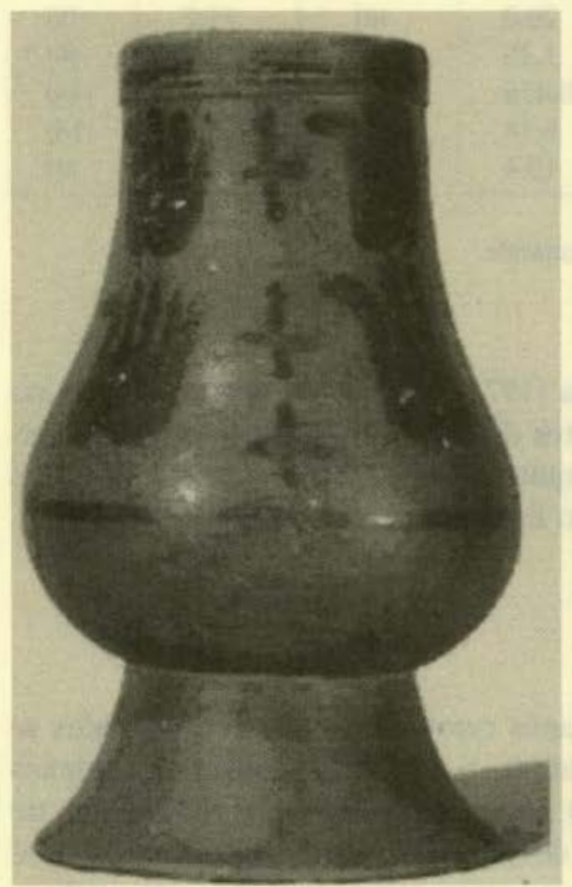

b

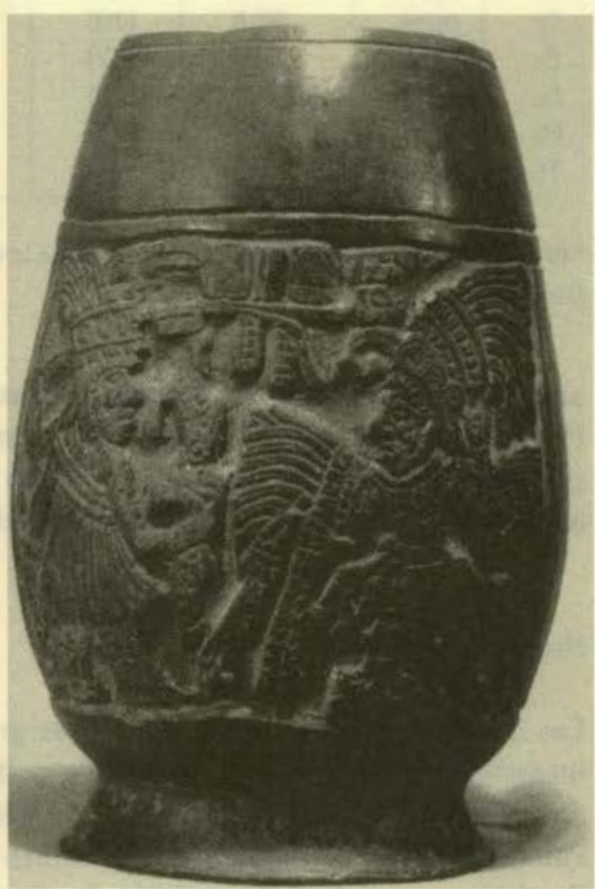

C

Figura 6. a. Grupo Cerámico Balancán, tipo Provincia Plano Relieve (Museo de Jonuta); b. Grupo Cerámico Silhó, tipo Yaltón negro sobre anaranjado; c. Grupo Cerámico Altar, tipo Pabellón Moldeado Excavado (a. Museo de Jonuta; b, c, desconocido)

fuente de producción de esta cerámica se ubicaría cerca del Usumacinta, como es el caso del río Pasión, que atraviesa por subestratos que no corresponden a formaciones geológicas ígneas (Bishop y Rands, 1982: 283). Con base en datos

Estudios de Cultura Maya. Vol. XXVI, 2005

Instituto de Investigaciones Filológicas/

Centro de Estudios Mayas, UNAM 
TABLA 2

ConceNTRACIONES ELEMENTALES PARA LOS GRUPOS DE PASTA FINA

\begin{tabular}{|l|l|r|r|r|r|r|r|}
\hline Elem & Unit & \multicolumn{2}{|c|}{$\begin{array}{c}\text { "Pabellon" } \\
\text { (n=83) }\end{array}$} & \multicolumn{2}{c|}{$\begin{array}{c}\text { FO-sur } \\
\text { (n=190) }\end{array}$} & \multicolumn{2}{|c|}{$\begin{array}{r}\text { FO-norte } \\
\text { (n=94) }\end{array}$} \\
\hline $\mathrm{Na}$ & $\mathrm{pct}$ & 0.675 & $(15)$ & 0.745 & $(17)$ & 0.645 & $(15)$ \\
$\mathrm{K}$ & $\mathrm{pct}$ & 2.28 & $(7.0)$ & 1.88 & $(9)$ & 1.90 & $(11)$ \\
$\mathrm{Sc}$ & $\mathrm{ppm}$ & 18.9 & $(6)$ & 16.3 & $(8)$ & 17.3 & $(9)$ \\
$\mathrm{Cr}$ & $\mathrm{ppm}$ & 494. & $(15)$ & 439. & $(11)$ & 430. & $(12)$ \\
$\mathrm{Fe}$ & $\mathrm{pct}$ & 5.46 & $(5)$ & 4.78 & $(8)$ & 5.02 & $(9)$ \\
$\mathrm{Co}$ & $\mathrm{ppm}$ & 36.3 & $(16)$ & 30.9 & $(9)$ & 32.2 & $(11)$ \\
$\mathrm{Rb}$ & $\mathrm{ppm}$ & 150. & $(11)$ & 113. & $(11)$ & 113. & $(14)$ \\
$\mathrm{Cs}$ & $\mathrm{ppm}$ & 5.00 & $(15)$ & 4.40 & $(12)$ & 4.30 & $(13)$ \\
$\mathrm{Ba}$ & $\mathrm{ppm}$ & 659 & $(15)$ & 487. & $(14)$ & 873 & $(26)$ \\
$\mathrm{La}$ & $\mathrm{ppm}$ & 48.0 & $(8)$ & 37.8 & $(7)$ & 39.5 & $(14)$ \\
$\mathrm{Ce}$ & $\mathrm{ppm}$ & 90.8 & $(10)$ & 70.0 & $(6)$ & 71.7 & $(8)$ \\
$\mathrm{Eu}$ & $\mathrm{ppm}$ & 1.54 & $(7)$ & 1.25 & $(6)$ & 1.27 & $(8)$ \\
Lu & $\mathrm{ppm}$ & 0.591 & $(11)$ & 0.478 & $(10)$ & 0.477 & $(14)$ \\
$\mathrm{Hf}$ & $\mathrm{ppm}$ & 7.23 & $(11)$ & 6.18 & $(10)$ & 6.06 & $(14)$ \\
Th & $\mathrm{ppm}$ & 13.5 & $(7)$ & 10.4 & $(6)$ & 10.8 & $(8)$ \\
\hline
\end{tabular}

* El número entre paréntesis es el coeficiente de la variación

FueNTE: Bishop, 2003

acerca de la distribución de tipos, Adams (1971:51) también postuló que el río Pasión pudo ser una de las posibles fuentes de la cerámica Pabellón. Sin embargo, aún se requiere determinar un nexo químico preciso con dicho río (para un análisis de la cerámica Pabellón Moldeado Excavado, véase Werness, 2003).

\section{Nuevos estudios composicionales}

Los datos derivados de los anteriores grupos composicionales determinados se integraron en una base de datos expandida ( $\mathrm{n}>2000$ ) que consta de cerámica anaranjado fino, gris fino, negro fino y la pasta fina relacionada de la región de Palenque. Para determinar los patrones de variación en el interior de la base de datos, se realizó un análisis de componentes principales. En este análisis, cada componente es una combinación ponderada, independiente y linear de todos los elementos seleccionados, incorporando aquellos que tienen una correlación interelemental (tabla 3).

Los componentes más grandes, que representan $69 \%$ de la variación total, sirven para separar buena parte de la loza anaranjado fino de las lozas gris fino y negro fino. En el lado izquierdo de la gráfica que aparece en la figura 4, la distribución de anaranjado fino está representada por tres elipses de $90 \%$ de 
TABLA 3

VALORES DE LOS COMPONENTES PRINCIPALES PARA EL CONJUNTO DE DATOS DE LA CERÁMICA PASTA FINA

\begin{tabular}{|c|c|c|c|}
\hline & 1 & 2 & 3 \\
\hline $\mathrm{Na}$ & -0.839 & -0.003 & -0.080 \\
\hline K & -0.892 & 0.157 & 0.017 \\
\hline Sc & -0.508 & 0.710 & 0.243 \\
\hline $\mathrm{Cr}$ & 0.687 & 0.280 & 0.429 \\
\hline $\mathrm{Fe}$ & -0.614 & 0.580 & 0.320 \\
\hline $\mathbf{R b}$ & -0.876 & 0.233 & -0.106 \\
\hline Cs & -0.736 & 0.180 & -0.263 \\
\hline La & 0.257 & 0.867 & -0.183 \\
\hline $\mathrm{Ce}$ & 0.379 & 0.817 & -0.181 \\
\hline Eu & 0.086 & 0.913 & 0.139 \\
\hline Lu & 0.310 & 0.783 & 0.065 \\
\hline $\mathrm{Hf}$ & 0.810 & 0.024 & 0.038 \\
\hline Th & 0.341 & 0.368 & -0.765 \\
\hline \multicolumn{4}{|c|}{ Variación de los componentes: } \\
\hline & 5.003 & 4.031 & 1.1 \\
\hline \multicolumn{4}{|c|}{ Proporción acumulativa de la dispersión total: } \\
\hline & 38.45 & 31.0 & 8.6 \\
\hline
\end{tabular}

confiabilidad (se utilizan elipses en lugar de mostrar cada punto de los datos para evitar un alto número de símbolos superpuestos). La elipse interna representa el grupo cerámico Silhó $(n=99)$. Los integrantes del grupo cerámico Balancán ( $n=143$ ) quedan dentro de la línea discontinua, mientras que la elipse externa es para el grupo cerámico Altar $(n=266)$. Hay que hacer notar que la amplia variación en el grupo cerámico Altar muy probablemente es resultado de haber incluido tiestos de anaranjado fino liso, que no pueden asignarse con mayor precisión en el esquema tipológico. En el espacio de los componentes compartidos por los tres grupos anaranjado fino se encuentran materiales Tres Naciones gris fino, la contraparte sin oxidación del anaranjado fino. En el centro y en el lado derecho de la figura 4 aparecen muestras del grupo cerámico negro fino Yalcox y del grupo cerámico gris fino Chablekal. Su distribución dispersa está en contraste con las áreas relativamente compactas de la gráfica, donde se encuentran los grupos anaranjado fino. La cerámica del grupo Chablekal cubre prácticamente todo el ancho de la gráfica, y se incluye en los intervalos de $90 \%$ de confiabilidad de los grupos anaranjado fino, en relación con los componentes 1 y 2 . Al realizar una evaluación estadística más detallada, es posible demostrar que, con excepción de las muestras que se encuentran dentro de las elipses de confiabilidad de la loza anaranjado fino, es muy baja la tendencia a formar grupos grandes y densos que pudieran representar lugares específicos de producción. 
La cerámica anaranjado fino permite conformar patrones composicionales discretos; los cambios menores en la composición al parecer se correlacionan con categorías tipológicas y diferencias temporales. Es más difícil definir patrones marcados para los datos de la cerámica más temprana de los grupos gris fino Chablekal y negro fino Yalcox, aun cuando sí existen patrones. Por ejemplo, la cerámica gris fino Chablekal de Jonuta se encuentra dentro de la elipse que rodea al grupo Balancán (figura 7), lo cual indica que las materias primas de la región de Jonuta, utilizadas para producir gris fino, se emplearon posteriormente para manufacturar cerámica anaranjado fino Balancán y Silhó. Además, la pasta fina Comalcalco gris (Peniche Rivero, 1973), que se recuperó en el sitio de Comalcalco al oeste, donde las arcillas están más dominadas por el drenaje del Grijalva, forma un grupo discreto y compacto en la gráfica. Hay muchos otros grupos pequeños que se encuentran en puntos con datos que muestran también

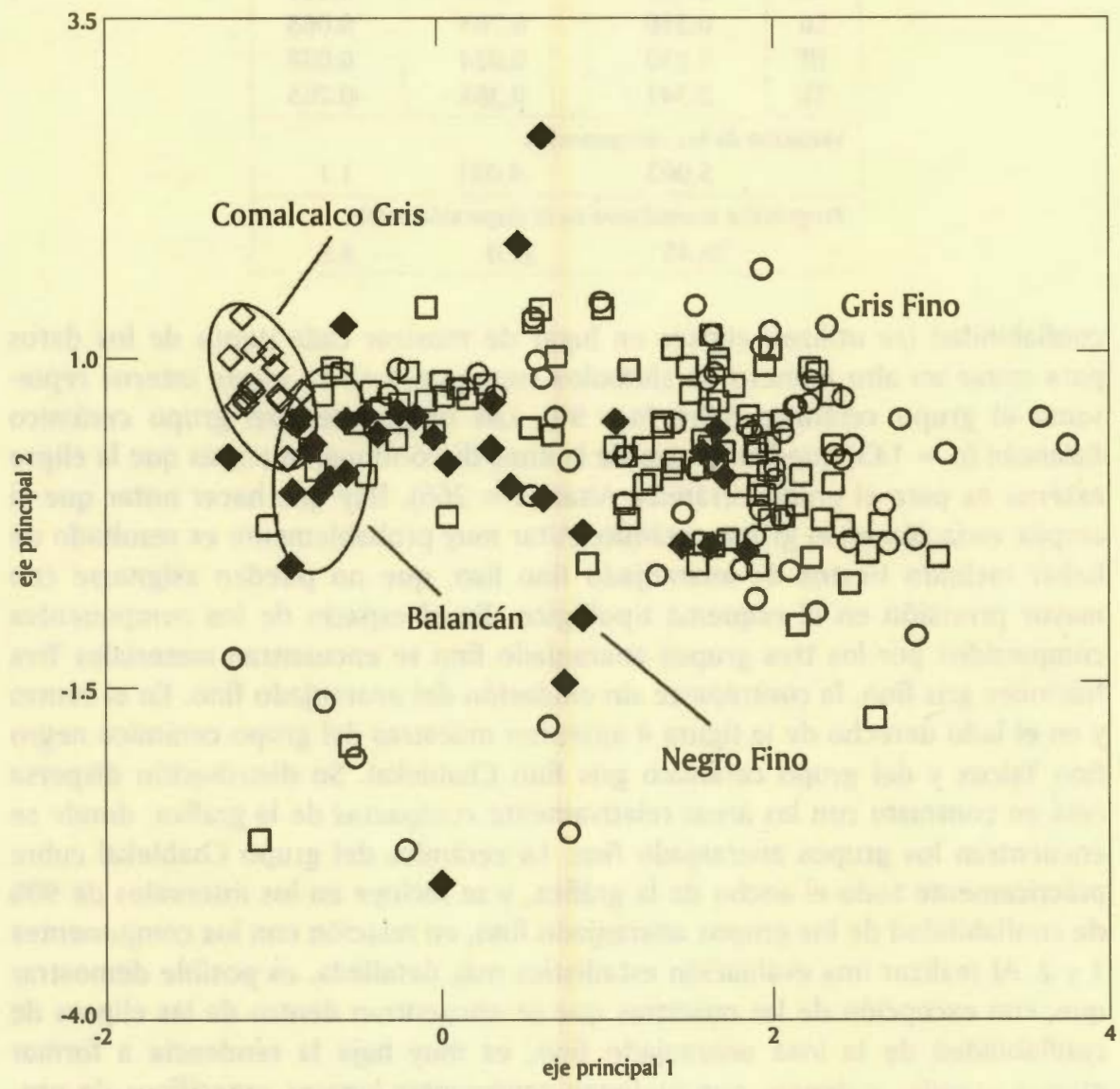

Figura 7. Gráfica de los componentes principales 
una distribución no estructurada de la cerámica gris fina. A menudo estos grupos tienen en común que proceden de un mismo sitio o se relacionan con sitios próximos entre sí (por ejemplo, Trinidad-Tierra Blanca, Pomoná-Chinikihá, y Piedras Negras-Yaxchilán). Por ahora estos grupos tienden a estar constituidos por un número limitado de muestras, por lo que no son susceptibles de una evaluación rigurosa y, en consecuencia, no se incluirán en la discusión que realizamos en este estudio.

Con la finalidad de enfocarnos más específicamente en aspectos de la variación composicional de la cerámica gris fino y negro fino, seleccionamos un grupo relativamente cohesivo de los materiales gris fino Chablekal de Cancuén, y se extrajeron los vectores característicos estandarizados de la matriz de varianza-covarianza. Estos vectores característicos son similares a los componentes principales pero están divididos entre la cantidad de variación en el vector, por lo que se crean vectores de unidad de longitud (tabla 4). Los datos para la cerámica restante que no es anaranjado fino, se proyectan a estos ejes de referencia y se realiza el análisis de grupos utilizando el método Wards. Los grupos resultantes, que se inspeccionaron para detectar información acerca de la pertenencia a un sitio común y para definir similitudes estilísticas al igual que homogeneidades químicas, constituyen la base para la siguiente discusión sobre algunos de los patrones más sobresalientes en los datos. Estos grupos de "prueba" no han sido sometidos a una evaluación estadística refinada o rigurosa para definir la pertenencia a grupos. No obstante, si se observa que los grupos se separan en cualquiera de las dimensiones, como es el caso del espacio elemental o de componentes, entonces estos grupos se separarán en un espacio multivariado más grande.

Los grupos distintivos tienen una fuerte representación de los sitios que se localizan en el bajo Usumacinta (Jonuta, Tecolpán, Trinidad, Tierra Blanca y San José del Río). La cerámica de Piedras Negras-Yaxchilán, en el Usumacinta medio, y Moral-Reforma en el río San Pedro Mártir, también está presente en los grupos, al igual que tres muestras de Palenque. Se muestran estos grupos en relación con los vectores característicos 1 y 2 , donde ocupan diferentes áreas de la gráfica, especialmente respecto al vector 1 (figura 8). El grupo en el lado izquierdo de la gráfica consta principalmente de materiales no decorados del gris fino Chablekal, cerámica de pasta fina sin tipo designado, y unas pocas muestras de cerámica Yalcox Negro. En contraste, la cerámica que se ubica en la parte alta del eje 1, tiende a ser de los tipos decorados Chablekal, incluyendo Chicxulub Inciso, Telchac Compuesto y Cholul Acanalado. Los análisis de arcillas de cauces que se recolectaron en el bajo Usumacinta también se incluyen en los grupos. La cerámica en el grupo no decorado, a la izquierda, es afín composicionalmente a arcillas que se usan en una fábrica de ladrillos frente al sitio de Trinidad. La muestra se tomó de un lugar donde se producen ladrillos con una mezcla de depósitos del primer y tercer dique. Son abundantes las partículas de vidrio volcánico. El grupo decorado consta de cerámica en la que el vidrio volcánico es 


\begin{tabular}{|c|c|}
\hline & 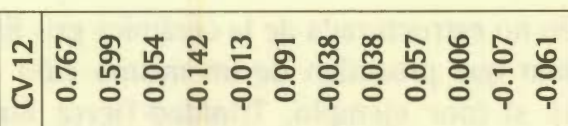 \\
\hline & 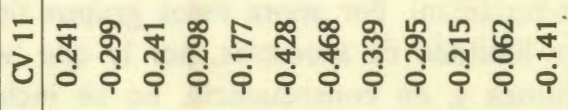 \\
\hline & 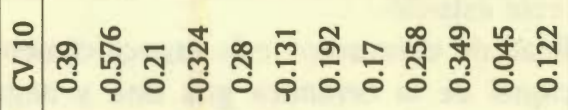 \\
\hline & 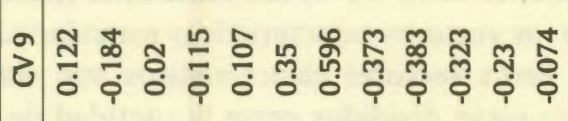 \\
\hline & 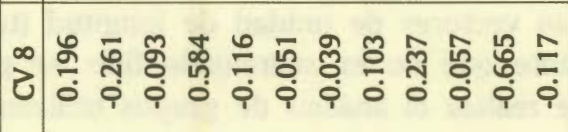 \\
\hline & 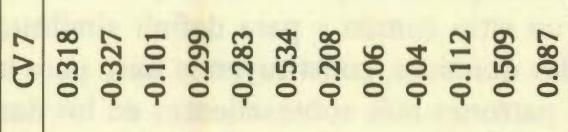 \\
\hline & 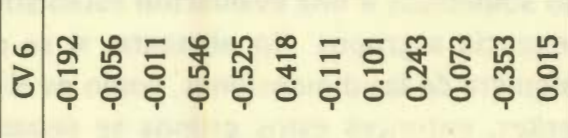 \\
\hline & 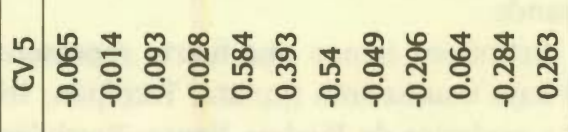 \\
\hline 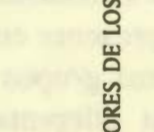 & 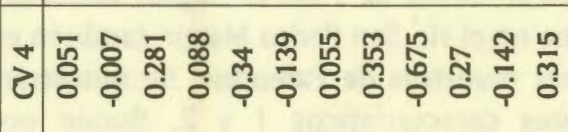 \\
\hline & 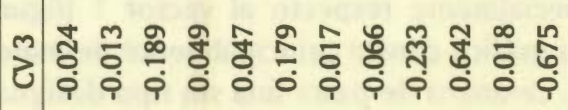 \\
\hline & 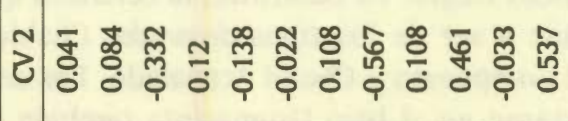 \\
\hline & 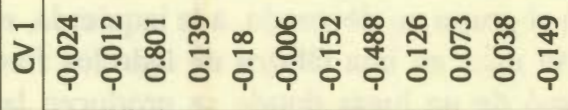 \\
\hline & 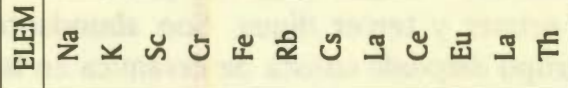 \\
\hline
\end{tabular}




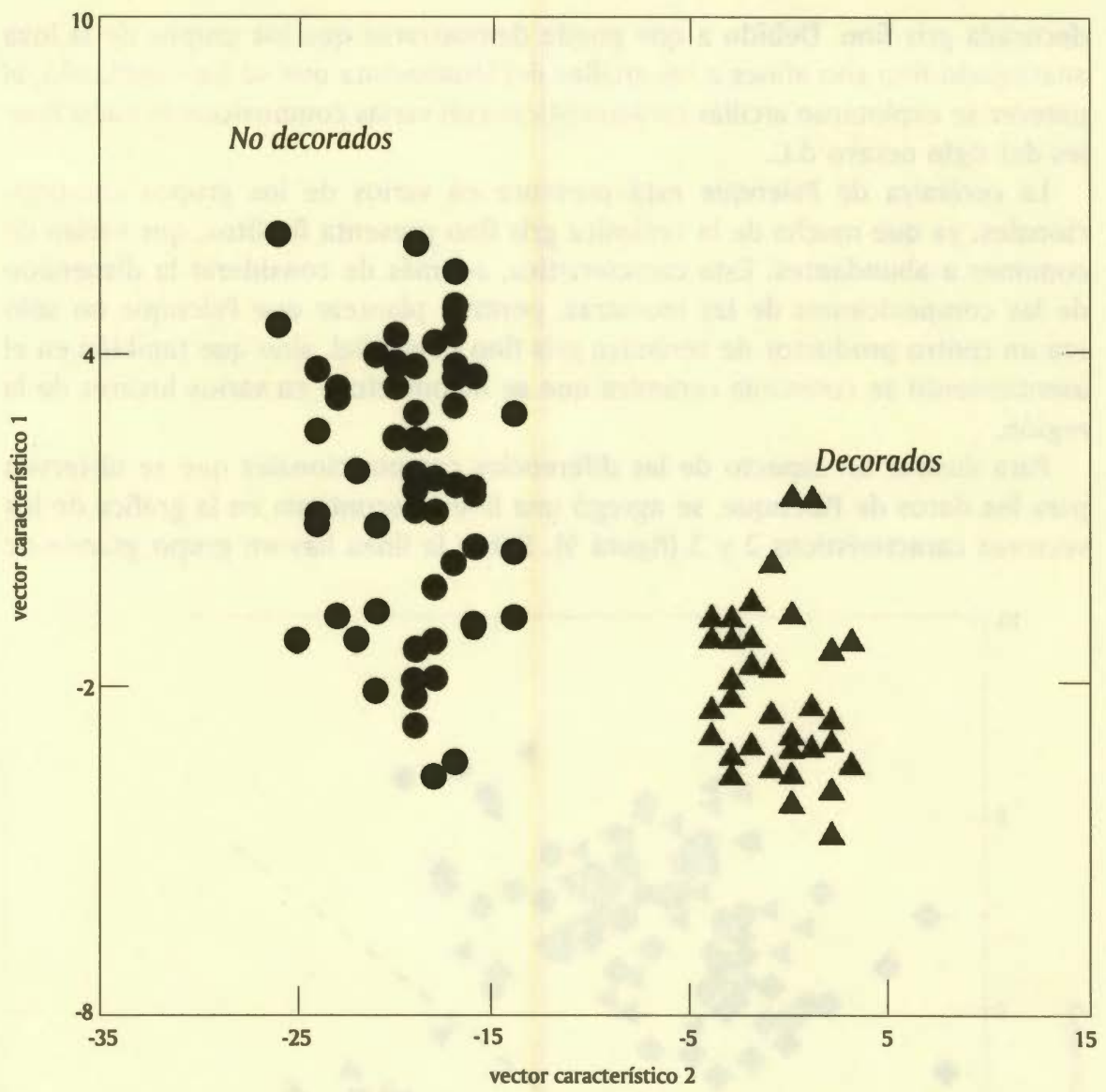

Figura 8. Gráfica de los vectores característicos estandarizados. No decorados y Decorados

menos abundante y es similar composicionalmente a una muestra de arcillas blancas de origen volcánico de Tierra Blanca. Es difícil determinar si las diferencias composicionales entre estos grupos son simplemente resultado de diferencias en los tipos, o de las características de las arcillas que se encuentran a lo largo del bajo Usumacinta, o bien resultan de cuestiones sociales que tal vez variaron con el tiempo.

Como hemos indicado, la loza anaranjado fino también se ha atribuido a la producción en el bajo Usumacinta, sin embargo difiere de la mayoría de la cerámica gris fino Chablekal, ya que tiene una matriz más micácea y casi el doble del contenido hierro elemental. Al utilizar la proyección de uno de los grupos más grandes de la loza anaranjado fino para los vectores característicos que se extrajeron del grupo de referencia Cancuén, en la gráfica la cerámica anaranjado fino tiende a ubicarse ligeramente separada de la distribución de la cerámica 
decorada gris fino. Debido a que puede demostrarse que los grupos de la loza anaranjado fino son afines a las arcillas del Usumacinta que se han analizado, al parecer se explotaron arcillas características con varias composiciones hacia finales del siglo octavo d.C.

La cerámica de Palenque está presente en varios de los grupos composicionales, ya que mucha de la cerámica gris fino presenta fitolitos, que varían de comunes a abundantes. Esta característica, además de considerar la dispersión de las composiciones de las muestras, permite plantear que Palenque no sólo era un centro productor de cerámica gris fino Chablekal, sino que también en el asentamiento se consumía cerámica que se manufacturó en varios lugares de la región.

Para ilustrar un aspecto de las diferencias composicionales que se observan para los datos de Palenque, se agregó una línea discontinua en la gráfica de los vectores característicos 2 y 3 (figura 9). Sobre la línea hay un grupo grande de

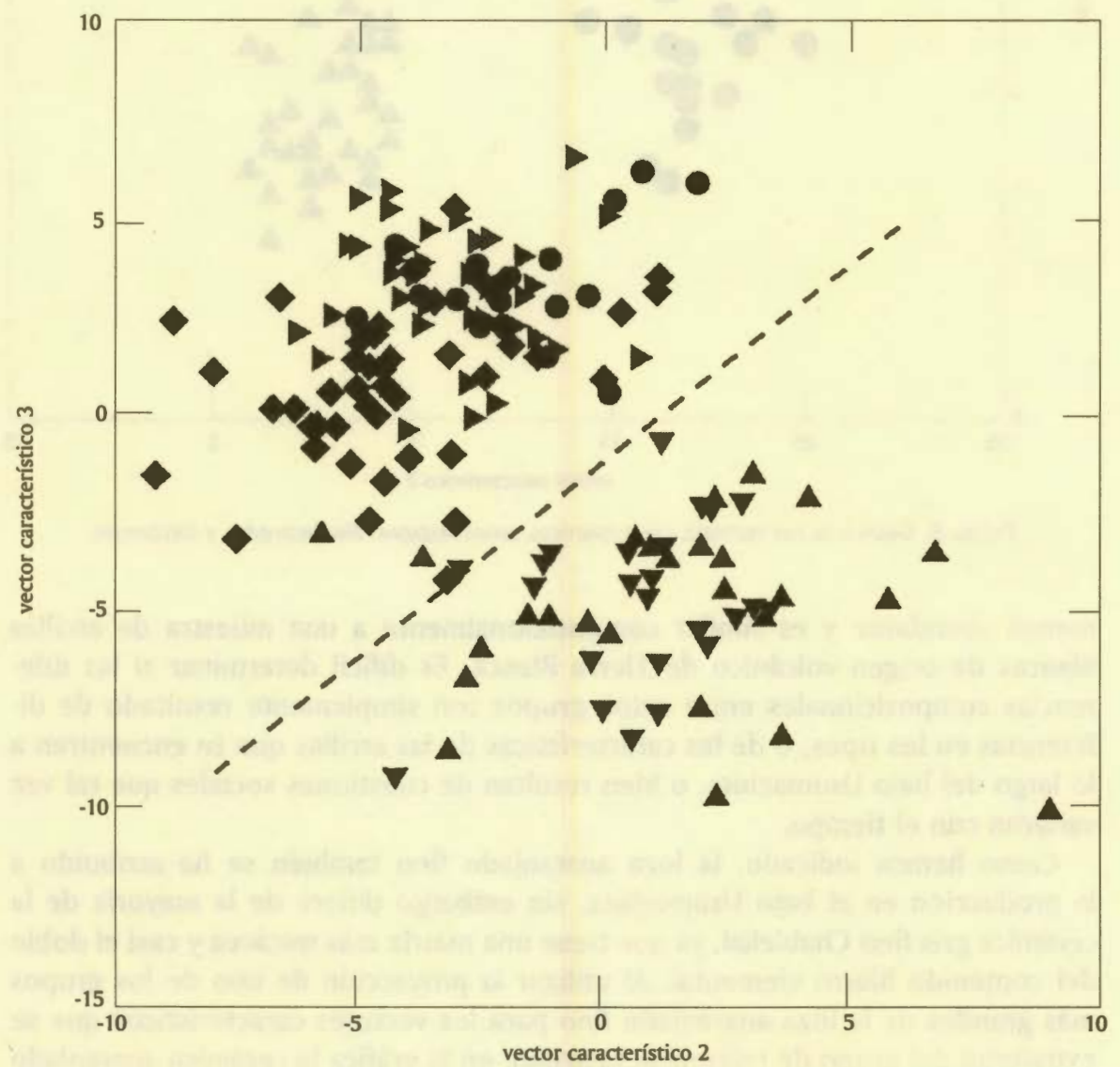

Figura 9. Gráfica donde se agrega una línea diagonal 
cerámica que procede de Palenque o de sitios en la zona inmediata a Palenque. En las pastas de la cerámica son comunes los fitolitos de ópalo y esporádicamente hay cantidades pequeñas de vidrio volcánico. Hay una alta representatividad de pastas finas rojas y café anaranjadoso. Bajo la línea, la cerámica de Piedras Negras, Aguateca y Reforma, al igual que la de Palenque, constituyen dos grupos, compuestos principalmente por los tipos Chicxulub Inciso y Telchac Compuesto, junto con Tekanto Inciso del grupo cerámico Yalcox Negro.

\section{Discusión}

En este estudio hemos hecho una breve mención de algunos de los patrones que se han definido a partir de la base de datos de la cerámica de pasta fina. En una futura publicación se incluirán todos los detalles acerca del muestreo y del análisis de datos (Bishop y Rands, en preparación). Por ahora nos hemos centrado en proporcionar un marco general acerca de la evolución de la cerámica de pasta fina, con particular referencia a la cuenca del Usumacinta.

A mediados del siglo octavo, al parecer, el grupo cerámico gris fino Chablekal surgió a partir de expresiones más tempranas de materiales negro fino. El hecho de que se observen similitudes en las formas, el tratamiento de los bordes y los patrones decorativos, posiblemente indica que hubo una fusión de preferencias palencanas con tradiciones cerámicas características de la planicie fluvial norteña del Usumacinta. Las variables composicionales, como es el caso de la presencia de fitolitos opalinos abundantes, núcleos negros y las características de la doble cocción de las piezas, constituyen una evidencia de que la producción de las piezas no se realizó en Palenque sino en zonas cercanas al asentamiento. Es posible asociar composicionalmente parte de la cerámica gris fino y negro fino, que contiene abundantes partículas pequeñas de vidrio volcánico intemperizado, con zonas productoras que se encuentran a lo largo del Usumacinta. En el caso de algunas muestras analizadas, no hay ceniza volcánica, posiblemente debido a la naturaleza intemperizada de las arcillas en algunos de los antiguos canales fluviales.

Aproximadamente hacia 760 d.C., entre la cerámica de Palenque y la de sitios en el río Pasión, los materiales gris fino Chablekal eran importantes, en especial para el caso de los tipos con mayor profusión decorativa, como Chicxulub Inciso y Telchac Compuesto. En el Petexbatún, por ejemplo, se ha identificado cerámica Chablekal en Dos Pilas, Aguateca, Arroyo de Piedra y, con menor frecuencia, en Tamarindito. Se encontró mucho mayor cantidad de gris fino Chablekal en Aguateca que en Dos Pilas, lo cual podría ser representativo de la época de la hegemonía regional de Aguateca después de la muerte del Señor 4 de Dos Pilas, en 761 d.C.

Recientemente se ha encontrado más cerámica Chablekal, incluyendo vasos muy elaborados y vasijas con forma de campana únicas, en las excavaciones de 
Inomata y Triadan en Aguateca, en pisos fechables para el momento en que se abandonó el sitio. El epigrafista Stanley Guenter propone que el ocaso del control de Dos Pilas sobre la región del Pasión habría posibilitado que el dirigente de Cancuén ampliara las actividades constructivas en el asentamiento (Guenter, comunicación personal, julio 2004), y podría interpretarse que se hubiera involucrado en una interacción interregional más amplia.

No obstante, al parecer no hubo una distribución igual de la cerámica Chablekal hacia los sitios localizados a lo largo de la vertiente del Usumacinta. Se ha encontrado una cantidad relativamente reducida de materiales Chablekal en Yaxchilan y Piedras Negras, es mucho menor su frecuencia en Altar de Sacrificios y Ceibal, mientras que es variable su presencia en sitios localizados en el Petexbatún. Sin embargo, en excavaciones realizadas aproximadamente a 500 metros al norte del palacio en Cancuén se encontró un taller de jade y en un depósito adyacente se recuperaron los restos de más de 100 vasijas Chablekal (Kovacevich et al., 2003).

Es claro que la cerámica distintiva gris fino Chablekal, de buena factura, decorada y de paredes delgadas, se distribuyó desde fuentes de producción ubicadas en la zona norte de las tierras bajas del occidente del área maya a sitios del alto Usumacinta y del Pasión. Obviamente la cerámica Chablekal fue popular, e incluso una representación familiar de un mono se copió en una pasta local en la Baja Verapaz, lugar en extremo alejado de donde se originó (figura 3d). Aun cuando hay evidencias de que la loza gris fino Chablekal fue objeto de intercambio hacia zonas costeras norteñas, como Dzibilchaltún, aparentemente el movimiento directo de esta cerámica se realizó por el Usumacinta hasta el Petexbatún y Cancuén, sin que llegara a Altar de Sacrificios y Ceibal.

La cerámica Chablekal que se encuentra río arriba en el Pasión es más homogénea en estilo y composición que los materiales gris fino identificados en la región próxima a Palenque, aparente foco del desarrollo y elaboración de la loza gris fino Chablekal. Además, algunas muestras de vasijas Chablekal que provienen de Palenque tienen el mismo patrón composicional que las procedentes del alto Pasión. Sin embargo, las vasijas de Cancuén y del Petexbatun tienden a presentar un patrón composicional que puede diferenciarse de la mayoría de la cerámica Chablekal de Palenque, lo cual refleja un cambio en el uso de recursos entre algunos de los productores de los materiales de los tipos designados como Chicxulub Inciso y Telchac Compuesto. Este cambio puede evidenciar una diferencia pequeña pero significativa temporal y/o en la organización de la producción de la cerámica Chablekal.

En las excavaciones que realizaron arqueólogos del INAH en Moral-Reforma, en Tabasco, en 1992 y 1993 (Juárez Cossío, 1992; 2003), se encontraron grandes cantidades de gris fino Chablekal, principalmente de los tipos Chicxulub Inciso y Telchac Compuesto. El sitio de Moral-Reforma se localiza cerca del río San Pedro Mártir, en una región donde hay terrenos agrícolas relativamente fértiles, con suelos que se desarrollaron a partir de fango marino y ceniza volcánica (Juárez 
Cossío, 1992: 13). En la planicie aluvial del río debieron encontrarse áreas donde el movimiento lento del agua en el terreno y las plantas que ahí crecían constituyeran condiciones favorables para la acumulación de fitolitos y la formación de arcillas ricas en materiales orgánicos, lo cual potencialmente cubriría las características requeridas en las materias primas de buena parte de la cerámica gris fino, según nuestros resultados de los análisis composicionales.

Son evidentes los vínculos entre Moral-Reforma y Palenque, ya que las composiciones de la pasta de la cerámica negro fino que se encontró en el sitio de Moral se corresponden con las muestras de Palenque. Además, el registro epigráfico documenta que Kan B'ahlam II, dirigente de Palenque, supervisó una ceremonia que se realizó en Moral-Reforma en 690 d.C. (Martin, 2003).

La ubicación de Moral-Reforma en el San Pedro pudo brindar una alternativa de transporte significativamente más ágil en comparación con el movimiento combinado por río y por tierra hacia los sitios río arriba a lo largo del accidentado Usumacinta, al igual que una vía estratégica de acceso al Petén Central. Palenque, como sitio dominante en la región, bien pudo ser un estímulo de gran importancia para el desarrollo de la cerámica negro fino y gris fino, además de ser un promotor del intercambio. Sin embargo, en años posteriores, Palenque sufrió una pérdida de control al igual que otros superpoderes mayas, mientras que Moral-Reforma, una vez que quedó fuera del control palencano, pudo haber buscado más beneficios derivados del intercambio de la cerámica gris fino Chablekal, inspirada en Palenque, con sitios río arriba en la región del Petexbatun, al igual que con Cancuén.

Los patrones composicionales de la cerámica gris fino Chablekal sugieren que muy probablemente los materiales que llegaron al alto Usumacinta y al río Pasión se produjeron en muchos lugares ubicados en una misma región general. A finales del siglo octavo, en la medida en que disminuyeron las amenazas bélicas y la región se recuperaba de la sequía, es muy posible que la cuenca del Usumacinta siguió constituyendo un canal para el movimiento de bienes hacia el norte, los cuales circulaban más libremente ante el vacío social que se generó con el colapso de las grandes casas dinásticas. Tal vez los artesanos que se encontraban en el área de manufactura de la cerámica Chablekal tuvieron más libertad para que las vasijas que elaboraban entraran al mercado a través de los canales preexistentes, de manera similar al área del taller de jade en Cancuén.

\section{Epílogo}

En los inicios del siglo ix de nuestra era, los elementos estilísticos de la cerámica de Palenque en épocas anteriores encontraron nuevas formas de expresión y popularidad en la loza anaranjado fino de la región del bajo Usumacinta. La loza gris fino volvió a ser popular o continuó siéndolo, pero como cerámica anaranjado fino sin oxidación, que es químicamente diferente a la loza gris fino 
Chablekal más temprana. En algún lugar a lo largo del Usumacinta surgió una variante composicional de la cerámica anaranjado fino que consumieron las poblaciones de Yaxchilán, los sitios del Pasión de Altar de Sacrificios y Ceibal, además de Punta de Chimino en el Petexbatún. En esencia, la cerámica Pabellón Moldeado Excavado marca el final de la distribución de la Pasta Fina en el núcleo de las Tierras Bajas Mayas, mientras que la Loza Silhó y otras lozas anaranjado fino más tardías del bajo Usumacinta llegaron a ser populares en las tierras bajas del norte.

La cerámica Chablekal y la cuenca del Usumacinta tuvieron un papel complejo en los acontecimientos ocurridos a fines del siglo octavo en el área maya, pero queda aún pendiente el registro preciso de esta historia.

\section{BIBLIOGRAFÍA}

Adams, Richard E. W.

1971 The Ceramics of Altar de Sacrificios. Cambridge, MA: Peabody Museum of Archaeology and Ethnology (Papers of the Peabody Museum, 63, núm. 1).

Berlin, Heinrich

1956 "Late pottery horizons of Tabasco, Mexico", Contributions to American Anthropology and History, 59: 95-153. Washington: Carnegie Institution of Washington (Publication 606).

Bishop, Ronald L.

1994 "Pre-Columbian pottery: research in the Maya region", Archaeometry of PreColumbian Sites and Artifacts, pp. 15-67, D. A. Scott y P. Meyers (eds.). Los Angeles: The Getty Conservation Institute.

2003 "Five decades of Maya Fine Orange ceramic investigation by INAA", Patterns and Processes: A Festschrift in Honor of Dr. Edward V. Sayre, pp. 81-92, L. van Zelst (ed.). Washington: Smithsonian Center for Materials Research and Education.

Garman Harbottle y Edward V. Sayre

1982 "Chemical and mathematical procedures employed in the Mayan Fine Paste Ceramics Project", Excavations at Seibal. Ceramics, pp. 272-282, J. A. Sabloff (ed.). Cambridge, MA: Memoirs of the Peabody Museum of Archaeology and Ethnology, 15, núm. 2.

Bishop, Ronald L., y Robert L. Rands

1982 "Maya Fine Paste ceramics: a compositional perspective", Excavations at Seibal. Ceramics, pp. 283-314, J. A. Sabloff (ed.). Cambridge, MA: Memoirs of the Peabody Museum of Archaeology and Ethnology, 15, núm. 2.

Foias, Antonia E.

1996 Changing Ceramic Production and Exchange Systems and the Classic Maya Collapse in the Petexbatun Region. Ph. D. dissertation, Graduate School. Nashville: Vanderbilt University. 
1977 "Changing ceramic production and exchange in the Petexbatun region, Guatemala", Ancient Mesoamerica, 8: 275-292.

1994 "El colapso Clásico maya y las vajillas de pasta fina en la región de Petexbatún", VII Simposio de Investigaciones Arqueológicas en Guatemala, 1993, pp. 563-586, J. P. Laporte y H. L. Escobedo (eds.). Guatemala: Ministerio de Cultura y Deportes, IDEAH, Asociación Tikal.

Harbottle, Garman, y Edward V. Sayre

1975 "Appendix: current status of examination of sherds of fine paste ceramics from Altar de Sacrificios and Seibal and their comparison with other Maya fine paste ceramics", Excavations at Seibal. Ceramics, pp. 241-253, J. A. Sabloff (ed.). Cambridge, MA: Memoirs of the Peabody Museum of Archaeology and Ethnology, 13, núm. 2.

Juárez Cossío, Daniel

1992 Informe de la primera temporada de campo del Proyecto Reforma, Tabasco, 1992. Instituto Nacional de Antropología e Historia, Centro Regional Tabasco.

2003 "Moral-Reforma: en La senda de Xibalbá", Arqueología Mexicana, XI (61): 3843. México: Raíces.

Kovacevich, Brigitte

2003 "Sistemas económicos y de producción maya: nuevos datos y retos en Cancuen", XVI Simposio de Investigaciones Arqueológicas en Guatermala, 2002, pp. 143-153, J. P. Laporte, B. Arroyo, H. L. Escobedo y H. E. Mejia (eds.). Guatemala: Museo Nacional de Arqueología y Etnología.

Martin, Simon

2003 "Moral-Reforma y la contienda por el oriente de Tabasco", Arqueología Mexicana, XI (61): 44-47. México: Raíces.

Ochoa Salas, Lorenzo

1976 "Notas preliminares sobre el proyecto: arqueología de las Tierras Bajas Noroccidentales del área maya", Estudios de Cultura Maya, X: 41-52. México: UNAM, IIFL, Centro de Estudios Mayas.

Peniche Rivero, Piedad

1973 Comalcalco, Tabasco: su cerámica, artefactos y enterramientos. Tesis, Escuela de Ciencias Antropológicas, Universidad de Yucatán.

Rands, Robert L.

1973 "The Classic Maya Collapse: Usumacinta zone and the northwestern periphery", The Classic Maya Collapse, pp. 165-206, T. P. Culbert (ed.). Alburquerque: University of New Mexico Press. 
1974 "The ceramic sequence at Palenque, Chiapas", Mesoamerican Archaeology: New Approaches, pp. 51-76, N. Hammond (ed.). Austin: University of Texas Press.

1977 Progress Report Mayan Ecology and Trade: 1967-1968, manuscrito. México: UNAM, IIFL, Centro de Estudios Mayas.

- y Ronald L. Bishop

1980 "Resource procurement zones and patterns of ceramic exchange in the Palenque region, Mexico", Models and Methods in Regional Exchange, pp. 1946, R. E. Fry (ed.), Society for American Archaeology, SAA, Papers 1.

y Jeremy A. Sabloff

1982 "Maya Fine Paste ceramics: an archaeological perspective", Excavations at Seibal. Ceramics, pp. 315-338, J. A. Sabloff (ed.). Cambridge, MA: Memoirs of the Peabody Museum of Archaeology and Ethnology, 15, núm. 2.

Reents-Budet, Dorie J.

1994 Painting the Maya Universe: Royal Ceramics of the Classic Period. Durham: Duke University Press.

Sabloff, Jeremy A.

1973 "Continuity and disruption during Terminal Late Classic times at Seibal: Ceramic and Other Evidence", The Classic Maya Collapse, pp. 107-132, T. P. Culbert (ed.). Alburquerque: School of American Research, University of New Mexico Press.

1975 Excavations at Seibal: Ceramics. Cambridge, MA: Memoirs of the Peabody Museum of Archaeology and Ethnology, 13, núm. 2.

1982 "Introduction: A brief informal history of the Maya Fine Paste Ceramics Project", Excavations at Seibal. Ceramics, pp. 268-271, J. A. Sabloff (ed.). Cambridge, MA: Memoirs of the Peabody Museum of Archaeology and Ethnology, 15, núm. 2.

Smith, Robert E.

1958 "The place of Fine Orange pottery in Mesoamerican archaeology", American Antiquity, 24: 151-160.

Werness, Marline Diane

2003 Pabellon Molded-carved ceramics: a consideration in light of the Terminal Classic Collapse of Classic Maya Civilization. M. A. Thesis. Austin: University of Texas at Austin. 